\title{
Mathematical Biology Education: Changes, Communities, Connections, and Challenges
}

\author{
John R. Jungck ${ }^{1}$ - Raina Robeva ${ }^{2}$ Louis J. Gross ${ }^{3}$
}

c) Society for Mathematical Biology 2020

Mathematical biologists have been leaders in many of the programmatic efforts over the past 60 years to reform both mathematics and biology education. This issue brings together a review of initiatives that have been particularly effective as well as addressing challenges that we need to face.

In planning the issue, we discussed how the variety of methods to cover mathematics for biology students have changed since the Cullowhee Conference on Training in Biomathematics held in 1961 at Western Carolina (see Rashevsky 1962) and the NRC/NAS publication of Bio 2010. When Bio 2010 initially appeared, a special conference at NIH organized by MAA brought together three funders: NSF, NIH, and HHMI to address the challenges and an edited collection of responses appeared in book format: "Math and Bio 2010: linking undergraduate disciplines" (2005) edited by Steen. Since the re-activation of the Educational Committee of the Society for Mathematical Biology in 1996, authors have been invited to submit educational articles to the Bulletin of Mathematical Biology, but this is the first special issue on education. The timing for this issue is propitious because it has been ten years since a National Academy of Sciences symposium celebration of the NRC/NAS (2003) publication Bio 2010. While three major publications resulted from that symposium: (1) a special issue of cbe Life Science Education (2010) edited by Jungck and Marsteller; (2) a special issue of Mathematical Modelling of Natural Phenomena (2011) edited by Jungck and Schwartz; and (3) Undergraduate Mathematics for the Life Sciences: Models, Processes, and Directions (2013) edited by Ledder, Carpenter, and Comar, there has been a significant change in the past decade and many resources were not described in

\footnotetext{
$凶 \quad$ John R. Jungck

jungck@udel.edu

Raina Robeva

RainaRobeva@rmc.edu

Louis J. Gross

gross@nimbios.org

1 University of Delaware, Newark, USA

2 Randolph-Macon College, Ashland, USA

3 University of Tennessee, Knoxville, USA
} 
these previous publications. We sought to supplement, update, and look to the future by developing an issue addressing challenges as well as assessing progress made since these earlier calls. We think that this opportunity of a special issue is important for our community.

Education has been valued by the SMB community for a long time. In the sixties and seventies, Chorbijian (1970) and Fred (Buck) McMorris led the original educational committee. After Gross (1994, 2000) organized two workshops at the University of Tennessee, follow up workshops were hosted by Iowa State (Jim Cornette), UNAM (National Autonomous University of Mexico-Jorge Velasco Hernandez), the University of Illinois (Sondra Lazarowitz and Jerry Uhl), and the BioQUEST Curriculum Consortium (Jungck 1997a, b). This led to the revival of the formal Education Committee in 1996 which has persisted ever since and drawn significant contributions at annual meetings and educational articles in this journal. Notably, Brynja Kohler's (Kohler et al. 2010) educational article in $B M B$ received the research article of the year award at the SMB international meeting held in Brazil. It remains as the trailblazer for setting a high standard for educational articles in $B M B$.

When the three of us met at NIMBioS in October 2018, we started our discussion by re-examining the special issue of Collegiate Mathematics (1985) about the "The Future of College Mathematics Conference/Workshop" which published the proceedings of the meeting that was held from 28 June to 1 July, 1982 at Williams College for which Roberts (1984) and Ralston (1984) wrote essays that were co-published with a series of responses from many academic mathematicians. Several of the responses were simply vitriolic and the resistance to better serve students was significant. Unfortunately, these responses were so similar to issues that we have to respond to today that we felt it was important to share a broad spectrum of contributions that would demonstrate how many resources are now available.

This $B M B$ issue demonstrates the breadth of initiatives that have occurred in the past decade as well as discussing current challenges that need to be addressed in order to improve the state of undergraduate mathematical biology education. In order to respect the diverse communities involved with and supportive of reform in mathematical biology education, we felt that it was incumbent upon us to reflect and honor this diversity. Thus, each solicitation was made to be inclusive and celebrate the work of multiple contributors from multiple institutions so that this issue would represent our community in a comprehensive fashion.

\section{Change}

Similar to the 1982 "The Future of College Mathematics Workshop" proceedings, we open this issue with four essays that explicitly used "change" in their titles. Three of these review the nature of educational research on undergraduate mathematics, biology, and some integrative approaches.

First, in "Introductory College Mathematics for the Life Sciences - Has Anything Changed?" Midge Cozzens (formerly NSF Director of the Division of Elementary, Secondary and Informal Science Education and a university president) and Fred Roberts (Director of DIMACS and author of the earlier clarion call) (2020) review 
the progress that has been made. They also discuss the disappointments about why so many earlier challenges still have not been addressed particularly well with regard to the continued failures to address retention and success of historically underrepresented groups in STEM education (National Academies of Sciences, Engineering, and Medicine 2016). One major impact on first-year college and university mathematics has been the nearly exponential increase in the number of entering students who have taken calculus in high school. They question whether this has been an overall positive development. They richly describe a wide variety of undergraduate mathematics textbooks that have been developed to bring many more biological applications into introductory college mathematics courses (primarily calculus). Despite the improvements that these texts have provided for undergraduate education, they raise the bar regarding what else is needed in order to enhance learning and serve the interests of our students. The issue of assessing the impact on learning through incorporation of biology in an introductory math course is challenging, but some tools are becoming available at least for biocalculaus (Andrews et al. 2017; Eaton and Highlander 2017; Taylor et al. 2020).

In the second article "Opportunities for Change in the First Two Years of College Mathematics" written by David Bressoud (former President of the MAA and a leader in national efforts in calculus reform) (2020), he reviews much of the mathematical educational literature on effective pedagogies that have been vetted by research and summarizes nationally funded reform efforts. He surveys ramifications of three major transformations in mathematics departments' mission to serve broad undergraduate education stimulated by: (1) the post-Sputnik scale-up of STEM education in general and an increased call for educating scientists and engineers; (2) the challenge raised by the impacts of computer science and discrete mathematics (again see Ralston (1984)); (3) the recognition that life science students are now the largest constituencies of first-year college and university mathematics courses. The massive infusion of funded "calculus reform" projects by NSF during 1988-1995 led to the flowering of multiple approaches to transforming calculus textbooks ( 8 of them were produced), to extensive use of technology, especially the use of computer algebra systems, and to introducing the importance of modeling. To quote Bressoud, "The reaction was swift and often vicious." But despite the backlash and the destruction of many programs developed during that era, "the inclusion of graphical and numerical representations of functions in addition to the purely algebraic, is now standard." Thus, the battle skirmishes were lost, but a war was won. In the 21 st century, this expansion has continued and a diversity of approaches have proliferated that are designed to meet actual needs of students, adopt and implement "mathematical practices," include interdisciplinary connections, use technology appropriately, focus on understanding and problem solving, and finally, to be more supportive of faculty involved with teaching introductory courses. He then notes the particular transition that occurred post the PCAST report (Engage to Excel, 2012). Finally, after NRC published its report: The Mathematical Science in 2025 (2013) and NAS the report, Data Science for Undergraduates (National Academies of Sciences, 2018), he suggests that "the challenge for the future is two-pronged:" (1) Engagement of students; (2) Curricular (change from what is easy to test to evaluation of effective preparation for future work). 
Third, the article by Melissa Aikens (a leader in biology education evaluation) (2020): "Meeting the Needs of a Changing Landscape: Advances and Challenges in Undergraduate Biology Education," does a similar analysis of the biological educational literature. In submitting her article, she laid down her fundamental aspiration: "Although undergraduate biology education has improved in the last 25 years, it has still largely remained "silo-ed" from other disciplines, particularly mathematics and physics. I argue that explicitly demonstrating the value of other STEM disciplines in our biology courses is an area in which the biology education community should invest time and resources, and I make recommendations for small steps that can be initiated by biology educators interested in pursuing this direction. I believe this manuscript will be of interest to readers of the Special Issue on Education by setting the context to understand commonly used evidence-based pedagogies and practices within biology classrooms, as well as the challenges that remain to be tackled, some of which could be alleviated by closer collaborations with mathematics instructors." She has succeeded. In particular, readers will relish the specificity of her recommendations as well as her conclusion that: "courses do not need to be completely overhauled in order to integrate biology, mathematics, and physical sciences. ... instructors can start by implementing small changes in their current courses, such as incorporating an interdisciplinary activity or module." She stresses that: "authentic problems are not simply putting a mathematics or physics problem in a biological context, but rather applying principles from another discipline or bridging interdisciplinary concepts to solve questions that biologists answer."

Finally, while Cozzens and Roberts (2020) already raised the issue of "the increasing importance and value of teaching data science," in "Changing the nature of quantitative biology education: data science as a driver," Robeva et al. (2020) explicitly focus on the contemporary challenge posed by the tremendous change powered by "big data." We review some variants of big data education and the differences between big data and big models. Particularly, our concern is for students to not only be enabled to explore and utilize big data to address complex, interdisciplinary problems that require non-linear, multivariate, and multidimensional techniques, but also to be acutely aware of the acute ethical and policy ramifications that working with big data entail. Correspondingly, we raise the issue of major transformations of education at a time when students have access to massive amounts of information, to powerful technology, and to computational, statistical, and visualization software, and how these might transform pedagogy and expectations for student learning.

\section{Communities}

Multiple communities play an extremely important role in developing a supportive culture for mathematical biology education. These include professional societies, associations, curriculum developers, and journals. In "Paying Our Dues: The Role of Professional Societies in the Evolution of Mathematical Biology Education," Greer et al. (2020) discuss four major players: (1) obviously, our own Society for Mathematical Biology, supports education through meetings (featured talks, minisymposia, posters, mentoring, education business meeting, and awards), journal papers, leader- 
ship, and web materials; (2) SIAM (Society for Industrial and Applied Mathematics) has both a section on life sciences and one on education; (3) MAA (Mathematics Association of America) was the organizer for the first major conference on mathematical biology education after the publication of Bio 2010 and produced a book based upon themes raised by its participants; it has a special interest group (Bio SIGMAA) that regularly organizes sessions at its annual education meeting (MathFest) and its sessions in the annual Joint Meetings (with AMS and SIAM); it has multiple opportunities for publishing articles, books, and newsletters; (4) BEER (Biomathematics and Ecology Education and Research) runs an annual conference which has built a national community and "created an academically inclusive atmosphere where the participants can network, share ideas, and build friendships." All these communities provide support for the kind of interdisciplinary scholarship and conversation among biologists, mathematicians, and education researchers needed to address challenges as we move forward and build productive collaborations. As they conclude, "these societies all have the opportunity to shape the nature of the scholarly work of mathematical biology education."

Besides professional societies, over the past 35 years, "communities of transformation" have developed and sustained STEM reform (Bernstein-Sierra and Kazar 2017; Gehrke and Kezar 2016). The articles here focus on four of these communities that have: (1) developed significant collections of resources; (2) run numerous workshops to help faculty develop interdisciplinary collaborations across mathematics and biology and educational materials; (3) provided access and searchability for open education resources (OERs); (4) fostered avenues for integrating computational tools into quantitative interdisciplinary education. In "Pathways to national reform of interdisciplinary learning across mathematics and biology," Akman et al. (2020) highlight the work of: (a) the BioQUEST Curriculum Consortium, a 34-year-old community that has continued to work nationally and internationally in all four of these arenas specializing on faculty and curriculum development that embraces learnercentered education; (b) the MathBench Biology Modules group that has developed a community of users of their introductory activities that emphasize the most common uses of mathematics in introductory college and university biology education and are meant to "complement traditional lecture- and lab-based in introductory biology courses" and which are most successfully used when well-integrated into such courses; (c) QUBES' (Quantitative Undergraduate Biology Education and Synthesis) the focus of which is "develop[ing] a cyberinfrastructure (Hub) to provide coordination for ... multiple education initiatives" which address "re-occurring issues between these siloed groups and individuals" and developed "Faculty Mentoring Networks" to help faculty not only with curricula but also conducting discipline-based educational research (DBER) in their classrooms and prepare tenure and promotion materials; finally, (d) IBA (Intercollegiate Biomathematics Alliance) which is deeply involved with the previously described BEER conferences and the Letters in Biomathematics journal as well as engaging multiple mathematics departments across the nation that "advance[e] biomathematics [by] conducting cutting-edge research, educating future scientists, providing platforms to advance the field, providing avenues to disseminate knowledge, and sharing contemporary research tools and expertise." 
The collective work of these four communities provides different avenues for engagement of faculty to find and collaborate with kindred professionals committed to the improvement of mathematical biology education. While there are overlaps between these communities, the distinctiveness of each community makes opportunities to serve faculty with divergent pedagogies, different areas of either mathematical or biological expertise, and comfort with using computational tools, social media, and massive data sets (Eaton et al. 2020). Some of these efforts have been reviewed for their effectiveness by Hoffman et al. (2016). Our mathematical biology education community needs to be aware that NSF (Porter et al. 2012) has invested heavily not only in these projects, but also in a variety of RCN's (research collaboration networks) such as NIBLSE (bioinformatics: Williams et al. 2019), STUB (Statistical Thinking in Undergraduate Biology: Keeling et al. 2020), REAL (R in Education and Assessment of Learning), and the Course-based Undergraduate Research Network (Dolan 2016).

The avenues for celebrating another aspect of undergraduate mathematical biology education center on the proliferation of opportunities for undergraduates to participate in research programs. While traditionally students were expected to contribute under the aegis of their faculty mentors (Gilbert 2004; Siegel 2004) others of us promoted opportunities for students to submit work on their own to be peer-reviewed by either faculty or other undergraduates (Jungck et al. 2004; Jungck 2015). In “The Case for Undergraduate Research Journals" editors Bendinskas and Melara (2020) describe and advocate for the importance that their journals play: the American Journal of Undergraduate Research, Spora: A Journal of Biomathematics, and the SIAM Undergraduate Research Online. All three journals publish high-quality articles that many faculty regularly praise for their originality and sophistication and often recognize that these articles are equal in quality to articles published in traditional peer-reviewed academic journals. Reciprocally, there is a value to the mentors of these undergraduate authors in achieving national recognition for the quality of their work. These journals "differ in their aims, scope, audience, etc.," but they share a common commitment: "peer review by experts in the field." They "play a valuable role in the overall undergraduate research experience."

\section{Connections}

In-service and pre-service teachers and their students have been engaged in multiple ways to appreciate the power, utility, and importance of mathematical biology to so many important contemporary medical, ecological, political, and socio-economic issues. Summer research opportunities, workshops, institutes, internships, and courses all play crucial roles in connecting to these communities.

Seshaiyer and Lenhart (2020) have been successful in "Connecting with Teachers through Modeling in Mathematical Biology." Their primary premise is "mathematical modeling can help transform pedagogical practices." Their modeling approach engages in-service high school teachers in a cycle of observing, theorizing, formulating, analyzing, simulating, validating, and prediction. A number of specific projects on biodiversity, ecology, showering versus bathing in terms of water conservation, areas of irregularly shaped bacterial colonies, sufficient vaccination to achieve herd 
immunity, and intracranial saccular aneurysms are used. While they emphasize that typical high school mathematics is applicable to many of these problems, they also introduced advanced topics like Fourier series and Laplace transforms. "Both authors have a lot of experience working with teachers from developing countries to engage best practices in teaching modeling." Thus, their approach has international potential for being adopted, adapted, and implemented in a variety of locales.

In "Undergraduate Quantitative Biology Impact on Biology Preservice Teachers," Mayes et al. (2020) stress the need to provide more opportunities in the classroom for authentic student experiences that demonstrate why quantitative reasoning $(\mathrm{QR})$ is an essential tool for learning biology. The QR process is presented in a framework of concept variables and their elements. They advocate for pedagogies that aid students in the discovery process by providing conceptual support during all stages of the QR process and against teaching from an "algorithmic perspective." The latter is particularly detrimental to pre-service biology teachers, as such practices then translate into similarly problematic approaches in K-12 education. Instead, Mayes et al. recommend that instructors 'take time to 'unpack' the reasoning and scaffold strategically," and help students discover how QR approaches lead to a better understanding of the underlying biology. The authors share specific project examples and QR tools used successfully in their classrooms and offer views on pedagogy for how to best prepare a "more confident and able teacher workforce for the next generation of K-12 students."

Enderling et al. (2020) have run a "High school Internship Program in Integrated Mathematical Oncology (HIP IMO)" for the past 5 years at Moffitt Cancer Center in Florida. The authors are leaders in the evolutionary therapy approach to cancer through which teachers learn about contemporary research devoted to extending peoples' lives in a dignified, respectful way that avoids the metaphorically militaristic approach. They emphasize the importance of learning about mathematical phylogenetics of tumor evolution in metastases, the evolution of resistance to chemotherapy, evolutionary game theory approaches to rugged dynamic landscapes, and a clear understanding of the ecology of cancers. This enhances the ideas of interdisciplinary scholarship involving multiple disciplines within both mathematical modeling (calculus, discrete mathematics, abstract and linear algebra, geometry and topology, computer programming, etc.) and biological investigations (immunology, ecology, evolution, genetics, molecular and cell biology, development, etc.). They use a "multi-model, multi-scale approach" to target "answering specific questions for different cancers." The interns "are involved in activities designed to foster the development of life-long research skills." Their program evaluates the learning outcomes, follows up on the trajectories of students who have participated in their program, and has led to publications both by the students and their research mentors. While they focus on "personalized computational oncology," their internship program serves as a successful model for engaging high school students in research which can "serve as motivation and blueprint for the development of similar programs." In particular, they found that the "mentor-mentee relationship [that] endures throughout ... the summer experience ... [was] vital to student engagement and success."

While we have not included particular examples of summer undergraduate research programs, we want to note the tremendous enduring success of Carlos Castillo- 
Chavez's Mathematical and Theoretical Biology Institute (Camacho et al. 2013; Castillo-Chavez et al. 2017) that has been offered at Cornell University, Los Alamos National Lab, and currently for many years at Arizona State University. This one program, which usually only has 24-35 students per summer, has accounted for the preparation of the majority of Ph.D. mathematicians in the US from historically underrepresented groups (African American, Hispanic, and Native American) as well as many females (Ellis et al. 2016) over the past 15 years even though mathematical biology is such a small subsection of the mathematics community. "In 2007, [MTBI] was recognized as a "Mathematics Program that Makes a Difference" by the American Mathematical Society; MTBI was also recognized with a 2011 Presidential Award for Excellence in Science, Mathematics, and Engineering Mentoring (Chowell et al. 2013)."

In their earlier work "What kind of explanation is a model?," Lehrer and Schauble (2010), noted: "Contemporary depictions of science have shifted from an emphasis on experimentation to the development, test, and revision of models, but by and large, school science has not followed this trend.... Teachers tend to associate inquiry with understanding and employing the methods of science; modeling and inquiry are often regarded as totally distinct enterprises. ... What, then, is important in determining whether and how young students successfully enter the modeling game? ... We favor tasks that emphasize problem posing, creating conditions for seeing, and development and evaluation of measurement. In addition, tasks that provoke variability of solutions and representational forms are more likely to support the development of a broad representational repertoire and an understanding of audience and design trade-offs. ... Therefore, we work with teachers to identify modeling contexts that afford a means of model test. ... However, many forms of model test are not immediately resolvable and require sustained conceptual effort and logical chains of reasoning. Often students need to mathematize, structure, and link complex forms of data (which may take time to collect and structure) to an initial question, and typically, the results include margins of uncertainty (which can sometimes be quantified)." Thus, in their current work in this issue: "Getting a Grip on Variability," Lehrer and Wisittanawat (2020) investigate directly what happens when students and their teachers move into experiences that stress the importance of active learning through modeling and "develop an epistemology of modeling."

\section{Challenges}

Agent-Based Modeling has been an important influence on the surge of a focus on modeling in undergraduate mathematical biology education, as noted in the Bodine et al. (2020) article herein: "Agent-based modeling and simulation in mathematical biology education." Part of this work was presented orally in a special session on agent-based modeling at the International Congress on Industrial \& Applied Mathematics (ICIAM) held in 2019; half of the presentations in the ICIAM ABM special session were focused on pedagogy. Some of the questions addressed include: How are simulations used nowadays in mathematics and biology courses? What are the main challenges? Has there been a change in the last decade or more? What has been 
done at their own institutions? What other programs use this approach? How are the programs similar (focus, goals, specific learning objectives, and outcomes) and how do they differ?

Agent-based models have had great appeal to biologists because they recognize that the assumptions upon which these simulations are built can reflect the biological interactions they investigate through field and laboratory efforts. Agent-Based Models, Individual-Based Modeling, Cellular Automata, and other bottom-up forms of mathematical modeling have been adopted well by the biological community because they have the advantage of frequently being tied to observable and measurable discrete interactions in and between biological systems. They value the ability to iteratively simulate what-if scenarios and revise their models when surprising counterintuitive results appear. Too often ODE and PDE models of biological problems have made assumptions about larger quite homogeneous populations, continuous time scales, and focused on the clarity that can arise from well-defined theorems and definitions. The popularity of agent-based approaches in biological education was highlighted by Gammack et al. (2013):

Agent-based models provide a powerful tool for research and exploration in many subjects including biology. The intuitive nature of the ABM framework makes the exploration of existing ABMs an inviting and informative tool for biologists regardless of their prior computational experiences. ... Working with agent-based models can engage students at all levels of Bloom's Taxonomy. Experiments using pre-programmed ABM simulations offer the opportunity to inform students in a classroom setting, helping them to understand and remember basic mechanisms that contribute to the global dynamics.... Through a careful evaluation of pre-existing models, students have an opportunity to develop a deep and memorable understanding of underlying behaviors. In addition, students are able to observe that a single simulation may have dramatically different results from what is most commonly observed in other simulations, thus reinforcing valuable lessons about stochasticity and the importance of repetition.

However, the mathematics community is frequently frustrated by the lack of analytical tools for simulation approaches that are more available from differential and partial differential equations. In a sub-section of an article entitled: "Mathematical Framework for Representing Agent-Based Models." Laubenbacher et al. (2013) have tried to address these concerns by demonstrating how the two approaches supplement, complement, and mutually inform one another. They outline how to move from agent-based models to sets of equations amenable to more analytically tractable methodologies. ... [After going through a specific example, they summarize] ...

Converting an agent-based model into a polynomial dynamical system [PDS] [over a finite field] provides us with a conceptual advantage, since rather than being limited to working with a computer simulation as our only means of analysis, methods and theory from abstract algebra and algebraic geometry can be used. ... Representation as a PDS provides a framework for efficient analysis using theory from abstract algebra. ... Much work remains to be done but, in the end, a combination of better algorithms, improvements in hardware, and 
dimension reduction methods is likely to provide for us a tool kit that will allow the solution of realistic large-scale optimization and optimal control problems in ecology, biomedicine, and other fields related to the life sciences.

Modeling biological systems through differential equations has its limitations, however. In many cases, the processes involved might be fundamentally discrete rather than continuous. For instance, in the case of a predator-prey relationship between two species inside an ecosystem, both populations are comprised of discrete individuals that engage in typically binary discrete interactions. Thus, it is not immediately clear whether one can apply methods such as differential equations, which assume that the quantities modeled vary continuously. In molecular biology, when we study regulatory relationships between genes inside a cell, these relationships are based on the interactions of discrete molecules. Modeling such systems using differential equations is based on two assumptions: first, there are many individuals involved, so that we can view them collectively as a continuous quantity; second, that we are able to describe the individual interactions in a "global" manner, as a term in a set of differential equations, usually involving one or more global parameters. Sometimes, both of these assumptions are justified, such as for large populations of bacteria or large quantities of chemicals in a fermenter. But at other times, one or the other, or both, of these assumptions fail.

Agent-based models lend themselves very well to a description of dynamical systems that arise from local interactions of many parts/agents, based only on local rules rather than on the configuration of the entire system at any given time. Also, it is very easy to represent a rich heterogeneous spatial environment that the agents navigate. Thus, the dynamics of the entire system, or its so-called global dynamics, "emerge" from these local interactions by applying the local rules repeatedly. In contrast, a system of differential equations, for instance, explicitly describes the global dynamics of the system upfront. Furthermore, all the specifications for an agent-based model are intuitive, in the sense that they are direct computational representations of recognizable features in the actual system. This leads to models that are more faithful to the system to be modeled and that are more accessible to domain experts.

In "The case for algebraic biology: from research to education," Macaulay and Young (2020) present a collaborative perspective review on the role of and need for algebraic methods at the undergraduate level, and specifically those coming from algebraic geometry. The article focuses on the importance of introducing such methods to the undergraduate mathematics, biology, and math-bio curricula, reviews what has been done to date nationwide, outlines the challenges, and provides ideas, opinions, and suggestions for what should be done and how. They address questions such as: How much algebraic geometry could/should be taught at the undergraduate level in connection to mathematical biology? In what courses? How much should students know to successfully transition to $\mathrm{PhD}$ programs in mathematical biology (or in $\mathrm{PhD}$ math programs with mentors who work at the interface of mathematics and biology)? 
Currently and in general, many such $\mathrm{PhD}$ students learn what they will need to know while already in graduate school. Is this optimal? Could we do better?

Finally, in "Mathematical Biology: Expand, Expose, and Educate!" Lee and Clinedinst (2020) raise one of the hardest, most fundamental challenges in undergraduate STEM education: how do we redress the systemic exclusion of historically underrepresented groups in mathematics, biology, and interdisciplinary programs that involve both. We have tremendous opportunities to recruit, retain, and advance minority students in our programs if we build inclusive, respectful, reflexive, and responsive curricula, practice vetted pedagogies that promote student retention and ontime graduation, place students in undergraduate research experiences, and demystify the processes that lead to success in post-graduate studies and dynamic professional careers.

\section{An invitation}

Obviously, there is a tremendous need for the mathematical biology community to continue these conversations. Thus, we invite authors to submit education-focused papers to the Bulletin of Mathematical Biology. The following guidelines for authors of education-focused papers were developed through conversations with the BMB editors:

Education articles may be of several different types. All articles are expected to be of broad interest to the mathematical biology community, and not focused on specialized topics of interest to particular sub-disciplines at an advanced level (e.g., appropriate only for advanced graduate courses, for example a novel way to construct a proof of a theorem that might be included in a graduate level course).

Education research articles These are expected to be consistent with, expand upon and utilize current education research, with an interdisciplinary component that includes both mathematical and biological concepts, utilizes biological concepts to develop comprehension of a mathematical concept, or utilizes mathematical concepts to enhance comprehension of a biological concept. These will typically include some formal assessment of learning associated with the approach, and evidence that the suggested approach enhances learning.

Module examples These are very brief (typically 2-3 journal pages) descriptions of novel methods to teach concepts that cross the math/biology interface. Ideally, these will include some evidence of assessment of learning, but if not, they should suggest methods for potential users to carry out such an assessment. Submissions are expected to include an on-line submission of detailed supplementary online materials (e.g., handouts, classroom use guide, project examples, sample exam questions) that allow the module to be readily utilized by an instructor desiring to incorporate the material.

Review articles These summarize the literature for broad pedagogical issues or methodologies (e.g., problem-based learning, peer-evaluation, collaborative learning, etc.) and how these apply specifically in a mathematical biology context.

Acknowledgements We sincerely appreciate particularly the support of the editors of BMB, Alan Hastings and Reinhard Laubenbacher as this special issue proceeded from initial conception through a long process 
of development. They were both appropriately interactive in making suggestions, as well as offering us the opportunity to organize the issue in alignment with the many voices in the mathematical biology education community we discussed this with as it progressed. Meghan Burke, education co-editor of BMB, was highly supportive as was the SMB Education Committee. It obviously takes a village to produce a special issue like this. We want to especially thank Helen Taylor, the Managing Editor, for all of her helpful advice and patience. Also, many reviewers significantly helped to improve the quality of the manuscripts through their extraordinary in-depth reviews and suggested revisions: Cynthia Bauerle, James Madison University; Sara Brownell, Arizona State University; Lauren M. Childs, Virginia Tech; Tim Comar, Benedictine University; Jim Cornette, Iowa State University; Kam Dahlquist, Loyola-Marymount University; Joseph Dauer, University of Nebraska-Lincoln; Robin Davies, Radford University; Eric Alan Eager, University of Wisconsin - La Crosse; Holly Gaff, Old Dominion University; Jennifer Galowich, St. Johns College; Luis Gordillo, Utah State University; Thomas Gorochowski, University of Bristol; Yaffa Grossman, Beloit College; Hannah Highlander, University of Portland; Susan Jungck, National Louis University; Vedham Karpakakunjaram, Montgomery Community College; Jonathan Keith, Monash University; Brynja Kohler, Utah State University; Eric J. Kostelich, Arizona State University; Drew LaMar, College of William and Mary; Chris Leary, SUNY Genesseo; Glenn Ledder, University of Nebraska-Lincoln; Paul Macklin, Indiana University; Ramit Mehr, Bar Ilan University; Jon Manon, University of Delaware; Jo Ellis-Monaghan, St. Michael's College and Korteweg-de Vries Institute for Mathematics (Netherlands); Sumona Mondal, Clarkson University; Claudia Neuhauser, University of Houston; Asamoah NKwante, Morgan State University; Gabrielle Pinter, University of Wisconsin-Milwaukee; Sarah Prescott, University of New Hampshire; Muriel Poston, Pitzer College; David Smith, Duke University; Gordon Uno, University of Oklahoma; Lisa Sattenspiel, University of Missouri; and Rachel Sherman, Delaware Technical Community College.

\section{References}

Aikens (2020) Meeting the needs of a changing landscape: advances and challenges in undergraduate biology education. This volume

Akman O, Eaton CD, Hrocenzik D, Jenkins K, Thompson K (2020) Pathways to national reform of interdisciplinary learning across mathematics and biology. This volume

Andrews SE, Runyon C, Aikens ML (2017) The math-biology values instrument: Development of a tool to measure life science majors' task values of using math in the context of biology. CBE Life Sci Educ 16(3):ar45

Bendinskas C, Melara LA (2020) The case for undergraduate research journals. This volume

Bernstein-Sierra S, Kezar A (2017) Identifying and overcoming challenges in STEM reform: A study of four national STEM reform communities of practice. Innov High Educ 42(5-6):407-420

Bodine P, Voit EO, Weisstein AE (2020) Agent-based modeling and simulation in mathematical biology education. This volume

Bressoud DM (2020) Opportunities for change in the first two years of college mathematics. This volume

Camacho ET, Kribs-Zaleta CM, Wirkus S (2013) The mathematical and theoretical biology institute-a model of mentorship through research. Math Biosci Eng 10(5\&6):1351

Castillo-Chavez C, Kribs C, Morin B (2017) Student-driven research at the mathematical and theoretical biology institute. Am Math Mon 124(9):876-892

Chorbijian T (1970) Mathematics for biology majors. Bioscience 20(11):652-657

Chowell G, Feng Z, Song B (2013) Special issue dedicated to Carlos Castillo-Chavez on his 60th birthday. From the guest editors. Math Biosci Eng 10(5-6):i-xxiv

Cozzens M, Roberts FS (2020) Introductory college mathematics for the life sciences: has anything changed? Bull Math Biol 82(7):1-15

Dolan EL (2016) Course-based undergraduate research experiences: current knowledge and future directions. Paper commissioned for the Committee on Strengthening Research Experiences for Undergraduate STEM Students Board on Science Education, Division of Behavioral and Social Sciences and Education Board on Life Sciences, Division of Earth and Life Studies

Eaton CD, Highlander HC (2017) The case for biocalculus: design, retention, and student performance. CBE Life Sci Educ 16(2):ar25

Eaton CD, Drew LaMar M, McCarthy M (2020) 21st century reform efforts in undergraduate quantitative biology education. Lett Biomath 7(1):55-66 
Ellis J, Fosdick BK, Rassmussen C (2016) Women 1.5 times more likely to leave STEM pipeline after calculus compared to men: lack of mathematical confidence a potential culprit. PLoS ONE. https:// doi.org/10.1371/journal.pone.0157447

Enderling H, Andor B, Brown G, Marusyk R, Silva A, Anderson AR (2020) High school internship program in integrated mathematical oncology (HIP IMO)—five-year experience at Moffitt Cancer Center. This volume

Gammack D, Schaefer E, Gaff H (2013) Global dynamics emerging from local interactions: agent-based modeling for the life sciences. In: Robeva R, Hodge TL (eds) Mathematical concepts and methods in modern biology: using modern discrete models. Academic Press, Boston, pp 105-141

Gehrke S, Kezar A (2016) STEM reform outcomes through communities of transformation. Change Mag High Learn 48(1):30-38

Gilbert SF (2004) Points of view: should students be encouraged to publish their research in student-run publications? A case against undergraduate-only journal publications. Cell Biol Educ 3(1):22-23

Gordon S (1985) Discrete topics in the undergraduate mathematics curriculum: how big a step should we take? New Directions in Two-Year College Mathematics. Springer, New York, pp 225-241

Greer ML, Akman O, Comar TD, Hrozencik D, Rubin JE (2020) Paying our dues: the role of professional societies in the evolution of mathematical biology education. Bull Math Biol 82(5):59

Gross LJ (1994) Quantitative training for life-science students. Bioscience 44:59

Gross LJ (2000) Education for a biocomplex future. Science 288:807

Hoffman K, Leupen S, Dowell K, Kephart K, Leips J (2016) Development and assessment of modules to integrate quantitative skills in introductory biology courses. CBE Life Sci Educ 15(2):ar14

Jungck JR (1997a) Biological aftermath: what can we learn from contemporary mathematics reform? BioQUEST Notes 7(2):1-13

Jungck JR (1997b) Ten equations that changed biology. Bioscene 23(1):11-36

Jungck JR (2015) Citizen Science: contribute to a Common Good, Collaborate, and Communicate! Am J Undergrad Res 12(3):2

Jungck JR, Marsteller P (eds) (2010) Special issue on mathematics in life science education. CBE Life Sci Educ 9(3)

Jungck JR, Schaeffer E (2011) Special issue on mathematics in life science education. Math Model Nat Phenomena 6(6):1-21

Jungck JR, Harris M, Mercuri R, Tusin J (2004) Undergraduates: do research, publish! Cell Biol Educ 3(1):24-26

Keeling E, Bunting J, Chance B, Roy S, Blank J, Tintle N (2020) STUB network: statisticians and biologists improving statistics education in introductory biology. FASEB J 34(S1): 1

Kohler BR, Swank RJ, Haefner JW, Powell JA (2010) Leading students to investigate diffusion as a model of brine shrimp movement. Bull Math Biol 72(1):230-257

Laubenbacher RC, Hinkelmann F, Oremland M (2013) Agent-based models and optimal control in biology: a discrete approach. In: Robeva R, Hodge TL (eds) Mathematical concepts and methods in modern biology using modern discrete models. Academic Press, Boston, pp 143-178

Ledder G, Carpenter H, Comar T (2013) Undergraduate mathematics for the life sciences: models, processes, and directions. MAA Press, New York

Lee S, Clinedinst L (2020) Mathematical biology: expand, expose, and educate! This volume

Lehrer R, Schauble L (2010) What kind of explanation is a model? In: Stein MK, Kucan L (eds) Instructional explanations in the disciplines. Springer, New York, pp 9-22

Lehrer S, Wisittanawat P (2020) Getting a grip on variability. This volume

Macaulay M, Young N (2020) The case for algebraic biology: from research to education. This volume

Mayes R, Long T, Huffling L, Reedy A, Williamson B (2020). Undergraduate quantitative biology impact on biology preservice teachers. This volume

National Academies of Sciences, Engineering, and Medicine (2016) Barriers and opportunities for 2year and 4-year STEM degrees: Systemic change to support students' diverse pathways. National Academies Press, Washington

National Academies of Sciences, Engineering, and Medicine (2018) Data science for undergraduates: opportunities and options. National Academies Press, Washington

National Research Council/National Academy of Sciences (2003) Bio 2010: transforming undergraduate education for future research biologists. National Academies Press, Washington

Porter AL, Garner J, Crowl T (2012) Research coordination networks: evidence of the relationship between funded interdisciplinary networking and scholarly impact. Bioscience 62(3):282-288 (Also found 
with alternative title: "The RCN (Research Coordination Network) experiment: Can we build new research networks.")

Ralston A (1984) Will discrete mathematics surpass calculus in importance? Coll Math J 15(5):371-373

Ralston A (2004) Research mathematicians and mathematics education: a critique. Not AMS 51(4):403-411

Rashevsky N (1962) A bird's-eye view of the development of mathematical biology. In: Proceedings of the Cullowhee conference on training in biomathematics: North Carolina State Univ Raleigh, pp 8-19

Roberts FS (1984) The introductory mathematics curriculum: misleading, outdated, and unfair. Two-Year Coll Math J 15(5):383-385

Robeva R, Jungck JR, Gross L (2020) Changing the nature of quantitative biology education: data science as a driver. This volume

Seshaiyer P, Lenhart S (2020) Connecting with teachers through modeling in mathematical biology. This volume

Siegel V (2004) Points of view: should students be encouraged to publish their research in student-run publications? Weighing the pros and cons of undergraduate-only journal publications. Cell Biol Educ 3(1):26-27

Steen L (2005) Math and Bio 2010: linking undergraduate disciplines. Mathematics Association of America, Washington

Taylor RT, Bishop PR, Lenhart S, Gross LJ, Sturner K (2020) Development of the biocalculus assessment (BCA). CBE Life Sci Educ 19(1):6

Williams JJ, Drew JC, Galindo-Gonzalez S, Robic S, Dinsdale E, Morgan WR, Triplett EW, Burnette IIII JM, Donovan SS, Fowlks ER, Goodman AL, Grandgenett NF, Goller CC, Hauser C, Jungck JR, NewmanI JD, Pearson WR, Ryder EF, Sierk M, Smith TM, Tosado-Acevedo R, Tapprich W, Tobin TC, Toro-Martınez A, Welch LR, Wilson MA, Ebenbach D, McWilliams M, Rosenwald AG, Pauley MA (2019) Barriers to integration of bioinformatics into undergraduate life sciences education: a national study of US life sciences faculty uncover significant barriers to integrating bioinformatics into undergraduate instruction. PLoS ONE 14(11):e0224288

Publisher's Note Springer Nature remains neutral with regard to jurisdictional claims in published maps and institutional affiliations. 